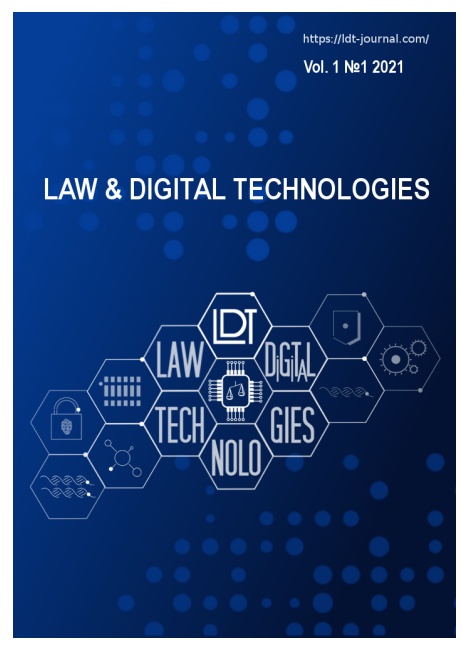

Law \& Digital Technologies. 2013-2023

ISSN 2782--2907

URL - $\underline{\text { http://ldt-journal.com }}$

All right reserved

№ 1 Volume 1. 2021

\title{
Russian Legal Framework for Digital Financial Assets
}

\section{Larisa Sannikova}

The State Academic University for the Humanities

Russian Federation, Moscow

\begin{abstract}
The article is devoted to the new Russian law on digital financial assets. The adoption of this law was an important step towards the formation of a legal framework for cryptoassets in Russia. Four types of legal framework models for crypto-assets around the world are identified: adaptation, fragmentary, experimental, and innovative. The Russian model of the legal framework for digital financial assets is close to an innovative model. The article analyses legal definitions of new legal concepts, such as "digital rights", "digital financial assets" and "digital currency". They represent different types of cryptoassets and are considered property under Russian civil law. A special legal status has been established forthe exchange operator of digital financial assets and for the operator of the information system in which digital financial assets are issued.The article describes the legal requirements for such participants in the cryptomarket, which are established to protect consumers from fraud and mismanagement. Particular attention is paid to the legal regulation of the issuance and circulation of cryptocurrencies, which the law names as digital currencies. Digital currency is not recognised as a legal means of payment in Russia.It can only be issued and circulated using the Russian information infrastructure.Based on the analysis of the new law, it is concluded that the Russian monetary authorities are not interested in establishing a complete and clear legal framework for participants in the cryptomarket.Their new initiatives aim to tighten regulation of the circulation of digital financial assets, especially digital currency.
\end{abstract}

Keywords list (en): digital rights, digital financial assets, digital currency, cryptoassets, cryptocurrency 
Acknowledgment:

Работа выполнена при поддержки гранта РФФИ № 18-29-16145 МК «Механизм правового регулирования отношений с использованием технологии распределенных реестров».

\section{Citation link:}

Sannikova L. Russian Legal Framework for Digital Financial Assets // Law \& Digital Technologies. - 2021. - V. 1. - № 1 C. 3-9 . URL: https://ldtjournal.com/s123456780015711-3-1/. DOI: 10.18254/S123456780015711-3

\section{Introduction}

2 On January 1, 2021, the Federal Law dated 31.07.2020 No 259-FZ "On the Digital Financial Assets, Digital Currency and on Amendments to Certain Legislative Acts of the Russian Federation" (hereinafter - the Law on DFA) came into force in Russia. The Law on DFA is intended to provide legal certainty for Russian holders of cryptoassets. Russia, like many other countries in the world, has gone a long way towards legalising crypoassets. At first, the Russian monetary authorities attempted to ban cryptocurrencies and other cryptoassets. Later, the necessity of creating legal regulation of crypto assets for the development of the digital economy in Russia was recognised. The federal project "Legal Regulation of the Digital Environment" became the starting point for the formation of the legal framework for cryptoassets. To ensure the legal conditions for the implementation and use of innovative technologies in the financial market, it was planned to adopt a federal act which was aimed at "regulating the circulation of cryptocurrencies and conducting ICOs (Initial Coin Offering), determining the status of digital technologies used in the financial sector and their concepts". However, a more general concept - "digital rights" - was the first to appear in legislation. For this, the corresponding amendments were made to the Civil Code of the Russian Federation. Digital financial assets are recognized as a type of digital rights in accordance with the Law on DFA. The concepts of "digital rights" and "digital financial assets" raise many questions for both legal scholars and practicing lawyers (Novoselova et al. 2019). The first section of this article analyses models of legal frameworks for cryptoassets in countries with crypto-friendly jurisdictions. Next, we discuss the legal essence of digital rights. The third section considers the legal definition of digital financial assets and their types. Section four describes the legal statuses of operators of information systems, in which DFAs are issued, and the legal statuses of DFA exchange operators. The fifth section deals with the legal regulation of the issue and circulation. Finally, we discuss digital currency (cryptocurrency).

\section{1. Models of legal frameworks for cryptoassets}

$4 \quad$ While many countries are in process of cryptoassets legitimization, there is still no country in the world with a comprehensive regulation of cryptoassets. There are several reasons for this. Firstly, cryptoassets, could not be comprehensively regulated by any national legislation, due to their extraterritorial character. Secondly, any legal regulation could slow down of an introduction of new technologies, such as blockchain, into economic activities. The legal regime of different countries of the world in relation 
to cryptoassets can be friendly, unfriendly or neutral. Countries with crypto-friendly jurisdictions establish various models of legal frameworks for crypto-assets which can be classified into several categories (Sannikova and Kharitoniova 2020): 1) An adaptation model, in which cryptoassets are regulated by existent legislation. For example, in the USA the Securities and Exchange Commission determines, based on the Howey test, whether tokens are securities like shares or bonds. If tokens are recognized as security tokens, then the legislation on securities applies to their issue. 2) A fragmentary model, in which cryptoassets are regulated by specific amendments made to existent legislation. For example, in Japan, cryptoassets' legislation was formed by amending existing laws: Payment Services Act No 59 of 2009; Financial Instruments and Exchange Act No 25 of 1948. 3) An experimental model in which cryptoassets are regulated by the legislation related to special economic zones. The Republic of Belarus has created a legal regulation of crypto activity only for residents of Hi Tech Park. Belarus Hi Tech Park is a special economic zone. The Decree of the President of the Republic of Belarus No 8 dated 21.10.2017 "On the Development of the Digital Economy" legalized crypto assets, but their circulation is limited and controlled. 4) An innovative model, in which the cryptoassets regulation is based on special legal acts. Malta became the first country in the world to regulate blockchain and cryptoassets by special laws. The Malta Digital Innovation Authority Act of 2018 establishes the Malta digital innovation centre to certify distributed ledger technology platforms. The Innovative Technology Arrangement and Services Act of 2018 regulates the registration procedures for crypto exchanges and other crypto markets. The Virtual Financial Assets Act of 2018 defines the legal regime of DLT (Distributed Ledger Technology) assets, including ICO procedures. Virtual financial assets include cryptocurrencies and payment tokens and exclude virtual tokens, electronic money and financial instruments. In 2019, Liechtenstein passed the Token and Trusted Technology Service Provider Act, known as the "Blockchain Act". Under this act, a token is recognized as a tool for the digital representation of a right. This is based on the concept of the Token Container Model. A security token contains a real asset. It may be a share, a bond, gold, real estate, and so on. If the token is not secured, it is an "empty container" that exists as a digital code, such as a bitcoin. Utility tokens within this concept contain the right to use the software (Software Usage Right). The examples of Malta and Liechtenstein shows the trend of national legislatures developing special legislation. However, the efficiency of such legislation is still questionable. The Russian legislation model is closest to the innovative model. However, it is not as comprehensive as as the legislation in Malta and Lichtenstein.

\section{2. The concept of digital rights in the Russian law}

6 In accordance with the Federal Law dated 18.03.2019 No 34-FZ "On Amendments to Parts One, Two and Article 1124 of Part Three of the Civil Code of the Russian Federation" digital rights were included in the list of objects of civil rights as a type of property rights (Art. 128 of the Civil Code of the Russian Federation). In Article 141.1 of the Civil Code of the Russian Federation, digital rights and other rights, named as such in the law, are recognized as obligatory. Their content and conditions for implementation are determined by the rules of the information system that meets the characteristics established by law. In English-language legal literature, "digital rights" denotes human rights applicable in the digital sphere (Marcus 2015; Goggin 2017). In 
Russian legislation, the term "digital rights" is used in a completely different sense. The attempts of the Russian legislature to create new terminology hinders the harmonization of Russian legislation in the field of the digital economy (Sannikova and Pescherov 2018), which can negatively affect the investment attractiveness of the Russian digital asset market. The term "digital rights" in relation to new digital assets, such as cryptocurrencies, tokens and so on, was not used in the legal literature prior to the adoption of this act. Therefore, the use of this term in the Civil Code of the Russian Federation caused extensive discussion in the legal community. Russian legal scholars also criticize the legal definition of "digital rights", in which new digital assets are qualified as "obligatory and other rights". They do not recognize digital rights as a special type of property rights along with obligatory, corporate and other rights. According to Kamyshansky (2019), digital rights represent obligatory and other rights that exist in a special information system (for example, in a blockchain). Most widespread viewpoint in Russian civil law regards digital rights as a special way of certifying rights (Novoselova et al. 2019). Vasilevskaya (2019) proposes to understand digital rights as a "digital way of fixing property rights". If cryptoassets are viewed only as a way of fixing rights, it must be recognized that the new way of fixing does not generate new rights. However, the assets tokenization processes have shown that cryptoassets owners receive new economic opportunities and legal rights. The legal definition of digital rights is not sufficiently complete and does not clearly explain this concept. For example, it is not obvious which digital assets are meant by digital rights. Some legal scholars believed that cryptocurrencies could also fall under the concept of digital rights (Efimova 2019). Others, such as Gongalo and Novoselova (2019), believe that the category of digital rights does not cover all types of crypto tokens. This discussion indicates the lack of an comprehensible and consistent concept of digital rights in Russian law. It seems that the concept will evolve as special laws on digital assets are adopted. Thus, the legal uncertainty was partially eliminated in the Law on DFA. Digital financial assets have been recognized as a type of digital rights.

\section{$7 \quad 3$. Digital Financial Assets: the legal definition and types}

8 According to Article 1 of the Law on DFA, digital financial assets are defined as digital rights which include: monetary claims; ability to exercise rights attaching to issuable securities; interest in the capital of a non-public joint stock company; and right to require transfer of issuable securities. The special feature of DFAs is that their issue, recording and circulation is carried out by way of making or amending entries in a distributed ledger-based information system or other information systems. DFAs do not include non-cash money, electronic money and uncertificated securities. Cryptocurrencies in the law are called digital currencies and are delimited from DFAs. Therefore, DFAs represent tokens that are capable of performing the role of financial instruments. The terminology used in the law does not make it possible to accurately correlate DFAs with the known types of token. The term "digital financial assets" is not used globally to regulate the crypto market. The exception is Malta, which has enacted the Virtual Financial Assets Act. The Law on DFA does not have no traditional division of digital assets depending on their functionality, such as payment, security and utility. Nevertheless, it can be concluded that the essence of the DFA is closest to security tokens. Hybrid tokens are also allowed, as indicated in Clause 6 of Article 1 of the Law on DFA "digital rights can be issued, including both digital financial assets and other 
digital rights". The Law on DFA establishes special rules for types of digital financial assets: - DFAs, certifying the possibility of exercising rights attached to mass-issued securities (Clause 1 of Article 12); - DFAs, certifying the right to claim their transfer of mass-issued securities (Clause 2 of Article 12); - DFAs, certifying the rights to participate in the equity of a joint-stock company (Article 13). The issue of DFAs, certifying the rights to participate in the equity of a joint-stock company, is regulated in the most detailed way. The possibility of issuing shares in the form of DFAs is provided only to non-public joint-stock companies, which have not previously carried out the issue of shares. Such an opportunity arises only upon the incorporation of a non-public joint stock company. The charter of a non-public joint stock company must provide for the ability to issue its shares in the form of DFAs. A share issuance in the form of DFAs must be registered by the information system operator in accordance with the rules of the respective information system. The issue of shares in the form of DFAs stipulates certain restrictions for the company. It will be unable to issue any mass-issued securities (including shares) in any form other than DFAs, convert the shares issued in the form of DFAs into ordinary shares in any form other than DFAs or become a public joint stock company. DFAs certifying the rights to participate in the equity of a joint-stock company can be identified as equity tokens. Other types of DFAs are difficult to associate to known types of tokens. For example, the Russian commercial bank "Expobank" accepted Waves tokens as collateral under the bank loan agreement (Shome 2020). The parties to the transaction qualified the cryptoassets as "other property" and not as digital rights. The legal nature of Waves tokens is unclear. Despite the headlines in the media about the first pledge of cryptocurrencies in Russia, the participants stated that these are non-payment tokens, but did not specify whether the tokens are security or utility, which significantly affects their liquidity. Therefore, legal uncertainty remains in relation to them. The Russian commercial bank Sberbank announced plans to issue a stablecoin Sbercoin (D'Andrea \& Partners Legal Counsel 2021). The bank's clients will be able to use sbercoins to purchase various green financing instruments such as green loans and green bonds on a special blockchain platform. However, according to S. Shvetsov, First Deputy Chairman of the Central Bank of the Russian Federation (hereinafter - the Bank of Russia), the Russian monetary authorities will not approve the issue of stablecoins backed by the Russian rubles (TASS 2020). It should be noted that the issuance and circulation of utility digital rights are already governed by the Federal Law dated 02.08.2019 No 259-FZ "On Raising Investments via Investments Platforms and on the Introduction of Amendments to Certain Legislative Acts of the Russian Federation". Utility digital rights include: - the right to demand a transfer of thing(s); - the right to demand a transfer of exclusive rights to intellectual property assets and/or the rights of use of intellectual property assets; - the right to demand that any work is done and/or any service is provided. Despite their name, utility digital rights cannot qualify as utility tokens., as they serve slightly different functions.

\section{9 \\ 4. Legal status of the operators according to the Law on DFA}

10 The Law on DFA established special legal status for the DFA exchange operator, and for the operator of the information system in which DFAs are issued. Only Russian legal entities (including credit institutions, depositories and stock exchanges), included by the Bank of Russia in the relevant register, may be an operator of the information system where DFAs are issued. To become registered, an entity intending to 
become an information system operator must have the rules of the information system approved by the Bank of Russia. The rules of the information system must contain a wide range of information specified in Article 5 of the law, for example, the rules for making changes to the algorithms of information system programs; requirements for users; rules for issuing DFAs, requirements for information security and operational reliability, and so on. The Law on DFA sets out certain requirements (for example, education and work experience in the respective area, reputational requirements, such as no convictions or administrative disqualifications, and so on) with respect to the executive bodies, other top officers of operators (chief accountant, head of internal control service) and beneficial owners holding 10 percent or more in the operator. The obligations of the operator are also established by the law. The operator must ensure the smooth and uninterrupted operation of the information system; the accuracy of the DFA information contained in the records of the information system; the restoration of access to the records of the information system for DFA holders if such access has been lost; and correctness of the implementation of the algorithms. The operator must also provide information about the user's digital financial assets on request of state bodies in cases stipulated by the law. If the operator violates the requirements of the law, the operator may be removed from the register by the Bank of Russia, which supervises the operator's activities. The operator is liable for losses incurred by the user of the information system, including those due to system malfunctions, and loss of information stored in the information system or inaccuracy of the information provided. All transactions with DFAs are completed through DFA exchange operators. Credit institutions, trade organisers and other legal entities meeting the requirements set in the Law may act as DFA exchange operators. In particular, they must have a share capital of at least RUB 50 million and net assets of at least RUB 50 million. The DFA exchange operator need to be registered by the Bank of Russia in a special register. It will approve the DFA exchange rules and obtain consent of the Bank of Russia for such rules. The DFA exchange operator may combine this role with that of the operator of the information system in which DFAs are issued. Therefore, the DFA exchange operator must meet the same requirements as the operator of the information system where DFAs are issued. The requirements set out in the Law on DFA for operators of the information system and DFA exchange operator are designed to protect DFA users from fraud and mismanagement. However, these requirements may hinder the development of blockchain startups in Russia.

\section{5. Legal regulation of issue, recording and circulation of DFAs}

12 The Law on DFA establishes a general procedure for the issue, recording and circulation of DFAs. DFAs may only be issued by a legal entity or an individual entrepreneur. The decision to issue DFAs is made in the electronic form and must be signed by an enhanced qualified electronic signature of the issuer. It must be published on the website of the issuer and on the website of the operator of the information system where DFAs are issued. This decision contains the information about the issuer, the operator of the information system and the relevant DFAs (including the type and the scope of rights certified by issuable DFAs, their number, payment terms, and so on). Such decision may be addressed to the public as a public offer or to specific parties (for DFAs certifying rights to participate in the equity of the non-public joint stock company). The first holder of DFAs becomes so entitled once a DFA crediting record is 
made in its favour in the information system in which the DFAs are issued. The holder of DFAs shall be recognized as the person who is included in the register of users of the information system and has a unique code giving such person access to the information about the DFAs owned by such person and permitting transfer of such DFAs by means of the information system. Holders of DFAs may carry out a variety of transactions, such as sale and purchase, exchange of DFAs, including exchange of DFAs for other digital rights, if such digital rights include both DFAs and other digital rights. The Law on DFA allows transactions with DFAs issued within foreign information systems. However, under the Instruction of the Bank of Russia dated 25.11.2020 No 5635-У, this right is only available to qualified investors. In addition, only qualified investors are permitted to transact with DFAs with value above RUB 600000.

\section{6. Digital currency: questions remain}

14 Investors are most interested in the legal regime of cryptocurrencies. The Law on DFA defines cryptocurrency as a digital currency. Digital currency is understood as a set of electronic data (a digital code or designation) contained in the information system that meets the following requirements: - which are offered and/or maybe accepted as a means of payment and/or as an investment; - which is not the monetary unit of the Russian Federation, the monetary unit of a foreign country and/or an international monetary or accounting unit; - in respect of which there is no person obliged to each holder of such electronic data, other than the operator and/or nodes of the information system. The description of the digital currency includes classic cryptocurrencies (payment tokens) such as Bitcoin, Ethereum, and so on. However, cryptocurrencies use blockchain or other distributed ledger technology to record transactions, the legal definition of digital currency makes no mention of such technologies. Therefore, any virtual currencies, such as computer game currencies, bonuses, and so on, can also be formally considered as digital currencies (Sangadzhieva and Pervunin 2020). The legal definition of a digital currency allows us to draw a conclusion about its relationship with the category of digital rights. Digital currency is not considered a type of digital financial asset. The legislation distinguishes digital currency from digital rights in order to restrict the issue and circulation of digital currency in Russia. Digital currency is not recognised as a legal means of payment in Russia. The rouble is the only official monetary unit in the Russian Federation. The prohibition on accepting digital currency as payment for goods or services applies to: - Russian legal entities; - branches, representative offices and other separate subdivisions of international organisations and foreign legal entities, if they are established in the Russian Federation and have civil legal capacity; - Russian individual tax residents (who spend at least 183 calendar days (or more) over 12 consecutive months in the Russian Federation). Additionally, no person is allowed to distribute any information about the offer and/or acceptance of digital currency as means of payment. However, the Law on DFA provides for the possibility of the issue and circulation of digital currency in Russia. Digital currency may only be issued using the Russian information infrastructure (domain names and network addresses belonging to the Russian domain extension; and/or information systems whose technical facilities are located in the Russian Federation, and/or software and hardware complexes located in the Russian Federation). Transactions and operations with digital currency, as a result of which it passes from one holder to another, can also only be carried out using the Russian information infrastructure. A digital currency 
holder has to inform the tax authorities of the existence of digital currency and transactions therewith as a condition for judicial protection of claims related to such transactions and/or operations. It should be noted that the holder of digital currencies has the right, not the obligation, to inform the tax authorities about digital currencies. But for civil servants, the obligation to provide information on digital financial assets and other digital rights, digital currencies owned by them and their family members (a spouse, underage children) is set by Decree of the President of the Russian Federation dated 10.12.2020 No 778. More detailed regulation of the issue and circulation of digital currencies is planned in a special law under consideration in the Russian State Duma. Experts expect a stricter legal regime for cryptocurrencies due to the negative attitude of the Russian monetary authorities.

\section{Conclusion}

16 The adoption of the Law on DFA required amendments to other laws, in particular, the Federal Law dated 07.08.2001 No 115-FZ "On Combating Money Laundering and the Financing of Terrorism", the Federal Law dated 26.10.2002 No 127FZ "On Insolvency (Bankruptcy)", the Federal Law dated 02.10.2007 No 229-FZ "On Enforcement Proceedings", and so on. It can therefore be concluded that a Russian legal framework for cryptoassets is being formed. Legal scholars are optimistic in their forecasts: "new opportunities open up to attract investment in the activities of individuals and legal entities, guarantees are established to protect inexperienced market participants" (Shestak and Yaresko 2020). Lawyers are more pessimistic about the consequences of the new law: "The project was developed without dialogue with market participants and received a lot of criticism regarding its definition of digital currency, as well as the regulation of circulating digital currency" (Sangadzhieva and Pervunin 2020). At the same time, legal scholars and experts acknowledge that the Law on DFA is "of a compromise nature, balancing public and private interests" (Rozhdestvenskaya and Guznov 2020). This compromise gives the appearance of creating a legal environment for the development of Fintech and the blockchain industry. However, new initiatives by the Russian monetary authorities aim to tighten regulations regarding the circulation of digital financial assets, especially digital currency. There are plans to establish not only administrative, but also criminal responsibility for tax evasion, the illegal issuance and trading of digital financial assets. The Bank of Russia demonstrates its negative attitude towards cryptocurrencies: "Cryptocurrencies do not have a single issuing authority; they do not guarantee a protection of consumer rights; their value is subject to significant volatility; it is illegal to use them to pay for goods and services in most countries; and they usually lack a single institution that would ensure their safety" (The Bank of Russia. n.d.). It is hoped that the digital rouble (central bank digital currency - CBDC) could become an alternative to cryptocurrencies in the Russian Federation (Rozhdestvenskaya and Guznov 2021). The above allows the conclusion to be drawn that the Russian authorities are not interested in establishing a complete and clear legal framework for participants in the cryptomarket. As a result, Russian companies have shown far less interest in investing in blockchain in 2020 than they did two years ago. This is a wake-up call for the development of the digital economy in Russia. 
1. References DÕAndrea \& Partners Legal Counsel. 2021. ÒSberbank To Launch Its First Digital Coin In Russia.Ó March 3, 2021.

https://www.dandreapartners.com/sberbank-to-launch-its-first-digital-coin-in-russia/ Efimova, Lyudmila. 2019. Cryptocurrency as an object of civil law. Economy and law 4: 17-25. Goggin, Gerard, Vromen Ariadne, Kimberlee Weatherall, Fiona Martin, Webb Adele, Lucy Sunman and Francesco Bailo. 2017. Digital rights in Australia. http://hdl.handle.net/2123/17587 Gongalo, Bronislav, and Lyudmila Novoselova. 2019. Is there a place for Òdigital rightsÓ in the system of objects of civil law. Perm Legal Almanac 2: 179-192. Kamyshansky, Victor. 2019. On digital technology and digital law. Power of the Law 1: 14-18. Marcus Gaia. 2015. Human rights and the new (ish) digital paradigm. https://sas-space.sas.ac.uk/6205/1/06marcus.pdf Novoselova, Lyudmila, Andrey Gabov, Alexander Savelyev, Artem Genkin, Sergey Sarbash, Anton Asoskov and Anatoly Semenov et al.Ê2019. ÒDigital rights as a new object of civil lawÓ. Law 5: 3154. Rozhdestvenskaya, Tatiana, and Alexey Guznov. 2020. Digital financial assets: problems and prospects of legal regulation. Actual problems of Russian law15 (6): 4354. DOI: 10.17803 / 1994-1471.2020.115.6.043-054. Rozhdestvenskaya, Tatiana, and Alexey Guznov. 2021. Digital currency: features of regulation in the Russian Federation. Law enforcement 5 (1): 58-67. DOI 10.24147 / 2542-1514.2021.5 (1) .58-67. Sangadzhieva, Tatiana, and Maxim Pervunin. 2020. The Virtual Currency Regulation Review: Russia https://thelawreviews.co.uk/title/the-virtual-currency-regulationreview/russia Sannikova, Larisa, and Alexander Pescherov. 2018. Legalization of cryptocurrency in Russia: problems and prospects. Property relationsin the RF 9: 64-74. Sannikova, Larisa, and Yulia Kharitonova. 2020. Digital Assets: Legal Analysis.

Moscow: 4 Print. Shestak, Viktor, and Alisa Yaresko. 2020. New approaches to the legal regulation of digital financial assets in the Russian Federation and the European Union. SSRN:Êhttps://ssrn.com/abstract=3723287 Shome, Arnab. 2020 ÒExpobank Writes RussiaÕs First Crypto-Backed Loan.Ó Finance Magnates. August 8, 2020.

https://www.financemagnates.com/cryptocurrency/news/expobank-writes-russias-firstcrypto-backed-loan/ TASS. 2020. ÒThe Central Bank opposed the issue of stablecoins on the Russian ruble.Ó November 30, 2020. https://tass.ru/ekonomika/10133239 The Bank of Russia. n.d. Accessed May 15, 2021. http://cbr.ru/eng/analytics/d_ok/dig_ruble/ Vasilevskaya, Lyudmila. 2019. Digital rights as a new object of civil rights: problems of legal qualification. Economy and law 5: 3-14. Russian legal framework for digital financial assets 


\section{Санникова Лариса Владимировна}

The State Academic University for the Humanities

Russian Federation, Moscow

\section{Аннотация}

Ключевые слова:

Дата публикации: 02.07.2021

\section{Ссылка для цитирования:}

Санникова Л. В. // Law \& Digital Technologies. - 2021. - Т. 1. - Vol. 1 №1 С. 3-9 . URL: https://ldt-journal.com/s123456780015711-3-1/. DOI: $10.18254 / \mathrm{S} 123456780015711-3$ 